\title{
What is an emergency?
}

\section{John Launer}

The word 'emergency' has always been a contentious one. For as long as I can remember, hospitals have tried to deter anyone who wasn't 'a real emergency' from attending their casualty departments. Indeed, they changed their name to 'Accident and Emergency' to emphasise this, although everyone still uses the older name anyway, or just 'A\&E' which somehow lacks the same force. In the same way, general practitioners (GPs) have for decades urged their patients not to turn up without an advance booking unless it was 'an emergency'. They have trained generations of surgery receptionists to use forms of words designed to separate the deserving from the apparently undeserving-mostly to no avail, or at the cost of creating considerable bad feeling among patients.

During the last dozen or so reorganisations of the National Health Service in England, several variations of first contact service have been introduced to try and tackle the perceived problem of patients who want to see doctors when doctors don't think they should. One of these is the phone advice service run by NHS Direct (recently threatened with abolition but then just rebranded). This seems to have increased the workload in the system by advising people to consult their GPs, just as they might have done in the first place. Similarly, walk-in centres were set up to give patients easy access and take the pressure off both GPs and hospitals, but they have rather muddied the waters by giving patients the explicit message that it is fine to expect immediate attention for any complaint-opposing the message that other services were told to convey.

\section{BLOCKED APPOINTMENTS}

In a similar experiment to sort out the system, the last government insisted that every GP surgery in England should block out significant numbers of appointments for release on the same day. Sadly, this has led to many surgeries having their phones jammed by callers first thing in the

Correspondence to Dr John Launer, London Deanery, London Department of Postgraduate Medical Education, Stewart House, 32 Russell Square, London WC1B 5DN, UK; jlauner@londondeanery.ac.uk morning, while queues form on the streets outside, and many of the most needy patients (including those with chronic illnesses) are unable to book regular appointments in advance.

Another strategy has been for GP outof-hours services to move into casualty departments in an attempt to separate the wheat from the chaff, but this has in some instances introduced even more confusion into the system. For example, the last time I thought I had a serious acute illness, I dutifully phoned the GP service and saw a competent colleague in a room beside A\&E within half an hour. He was concerned about me and phoned the medical registrar who agreed to see me on the ward as soon as possible. The impression of speed and efficiency was then rather spoiled when I took the GP's note to the A\&E reception desk $5 \mathrm{~m}$ away, and had to wait for a further hour before seeing a triage nurse. She took me through a laborious and pointless computer questionnaire covering all the systems in my body. Only then was I promoted to the status of a 'real emergency' (I had a suspected pulmonary embolus) and allowed through the security doors to see the registrar. I needn't have bothered to call the GP in the first place.

\section{CRACKING THE PROBLEM}

Having seen so many failed attempts over several decades to crack this problem, I'm far from confident that this will happen effectively. However, there are clearly some prerequisites for doing so. The first and most obvious one is to drop the word 'emergency' altogether. Self evidently, it means entirely different things to different people. It is too infused with subjective judgement, and its meaning is too variable according to context to have any value as a scientific term. (To take just one example, a mild case of viral croup in an infant is an emergency to a new parent who has never heard a croupy cough before.) We possibly also need to separate the notion of an accident or injurysomething relatively obvious and uncontested-from that of an emergency. Physical injuries require different resources and skills from other kinds of problem, and there is no logical reason to lump the two together.
Next, we need to accept that it is largely our job and not the patient's to make the distinction between what needs urgent attention and what does not. I recently diagnosed a meningococcal rash in a 4-year-old child who attended the surgery and was otherwise almost entirely well. For the sake of that achievement-only the second case I have seen in 28 years-I will happily accept having seen tens of thousands of mildly snotty toddlers over the years, giving their anxious parents a bit of friendly advice and education, and seeing them on their way in less than $5 \mathrm{~min}$. We cannot, in other words, preach the importance of our own expertise and at the same time berate people for making use of it. There is also little evidence that expensive campaigns of public education significantly alter people's ability to act as their own diagnosticians or reduce their consulting rates, whereas face-to-face explanations in the consultation do affect this.

A further step we need to take-and one that I suspect may be particularly difficult for managers - is to acknowledge that a large proportion of people will always take their pressing concerns exactly where they want to, and when they want to, regardless of anything we tell them. In some cases this is because they don't know or understand the complicated and overlapping systems that the health service now runs, which is hardly surprising. In other cases it is because they simply don't care about these because their immediate sense of their needs overrides their respect for ours, which is perfectly sensible adaptive behaviour. Given the choice between waiting ages in somewhere they are 'meant' to go, or being seen swiftly if impatiently by another service, they will intelligently choose the latter.

\section{MISMATCH IN DEMAND}

Of course, any solution will need to recognise that there is always likely to be a mismatch between demand for an immediate medical opinion and our capacity to provide it. Having said that, this is a historical problem of resources that doesn't exist in every developed country, and it isn't the fault of the patients. (In some countries like Japan, it is virtually non-existent.) We need to be frank about the mismatch, fit the time we can offer to the staffing available, and not dump on the patients as a consequence or blame them for being 'inappropriate attenders'. To state the obvious, a service that is open must be an open service. 
Either it has to limit entry to strict and indisputable criteria-like patients arriving by ambulance-or it has to be designed to accept everyone and to take things from there.

Making the services more complex, more restrictive or more rigid hasn't worked. Neither has bombarding the public with instructions. Nor has the confusion of financial modelling and so-called 'demand management' with clinical sense. Paradoxically, going with the flow may be the best solution, perhaps the only one. Instead of trying to deter people from seeking quick care, we might create a different climate where people expect to be seen quickly but realise these encounters must be brief. It is quite likely that fast-track services could be perfectly adequate for this purpose if they weren't complex and duplicated, were set up in the places that patients actually chose to go, and were staffed with people trained to make swift decisions across the whole spectrum of serious and non-serious medical conditions. Removing the largely spurious notion of an 'emergency' would be a good way to start.

Competing interests None.

Patient consent Obtained.

Provenance and peer review Commissioned; externally peer reviewed.

Published Online First 11 November 2010

Postgrad Med J 2010;86:745-746.

doi:10.1136/pgmi.2010.112672 